\title{
Intra-arterial perfusion-based therapies for regionally metastatic cutaneous and uveal melanoma
}

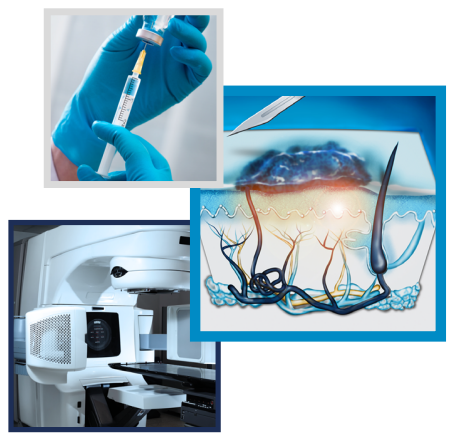

\author{
Kristy K Broman ${ }^{1}$ (i) \& Jonathan S Zager*,1 \\ 'Department of Cutaneous Oncology, Moffitt Cancer Center, Tampa, FL 33612, USA \\ *Author for correspondence: Tel.: +1 813745 1085; Jonathan.zager@moffitt.org
}

Locoregional disease remains a challenging problem in cutaneous melanoma and uveal melanoma. Arterial-based chemoperfusion strategies enable regional therapy delivery with minimal systemic toxicity. Herein we discuss intra-arterial therapies for in-transit cutaneous melanoma of the extremity including hyperthermic-isolated limb perfusion and isolated limb infusion. We also discuss open (isolated hepatic perfusion) and percutaneous hepatic perfusion techniques for isolated liver metastases from uveal melanoma. We review the current state of knowledge with respect to indications, procedural techniques, outcomes and expected toxicities for intra-arterial chemoperfusion for locoregional melanoma metastases.

First draft submitted: 1 March 2019; Accepted for publication: 13 June 2019; Published online: 2 September 2019

Despite dramatic advances in medical and surgical management of melanoma, locoregional disease remains a considerable problem. Approximately 4-10\% of cutaneous melanoma recurrences present as in-transit disease [1-3]. Additionally, as survival improves for patients with widespread metastases, locoregional disease can become a source of significant symptoms. Regional delivery of chemotherapy represents one treatment option for unresectable and symptomatic locoregional cutaneous melanoma.

Uveal melanoma is distinct from cutaneous melanoma in that over $50 \%$ of all patients will develop metastases, which may occur several years after treatment of the primary tumor $[4,5]$. In $80 \%$ of cases, metastatic disease is confined to the liver [6-8]. Historically, median survival after diagnosis of metastatic uveal melanoma is $2-9$ months [68]. Unlike cutaneous melanoma, systemic immunotherapy is minimally effective against uveal melanoma, producing short duration responses in 5-10\% of patients [9]. Given its unique presentation and refractoriness to systemic treatment, liver-directed therapies including intra-arterial chemoperfusion offer a targeted approach.

The concept of regional delivery of chemotherapy was first described over six decades ago, propelled by the development of the extracorporeal bypass machine for cardiac surgery and the establishment of effective chemotherapy to treat cancer. A mechanism to deliver higher doses of chemotherapy directly at the metastatic disease while minimizing systemic toxicity, regional chemoperfusion remains an important therapeutic tool today.

\section{Intra-arterial therapies for cutaneous melanoma of the extremity}

The upper and lower extremities are well suited for arterial-based therapies given the relative ease of isolating blood flow to and from the affected site. Regional limb therapy is an option for patients with in-transit disease that is limited to the extremity and is too extensive or refractory to simple excision or intralesional therapy. It can also be used as a bridge to surgical resection to render a patient free of disease. When distant disease is present, it may be considered for palliative purposes to treat symptomatic locoregional disease, but does not impact distant foci.

Two intra-arterial infusion strategies exist, both of which isolate circulation to and from an involved extremity, creating a closed circuit with an extracorporeal pump for regional delivery of chemotherapy (Table 1). The mainstay chemotherapeutic agent is L-phenylalanine mustard (melphalan), a cytotoxic agent with unique responsiveness to hyperthermic and acidotic environments [10]. Dosing for extremity infusions is based on limb volume, which can be determined by water displacement or sequential circumferential measurements along the length of the limb [11,12].

Future $\because \%$ Medicine 
Table 1. Comparison of hyperthermic isolated limb perfusion and isolated limb infusion.

\begin{tabular}{|lll}
\hline Technical aspect & Hyperthermic isolated limb perfusion & Isolated limb infusion \\
\hline Technique & Open, surgical vessel cannulation & Minimally invasive, percutaneous vessel cannulation \\
\hline Flow rate & $400-600 \mathrm{cc} / \mathrm{min}$ & $80-120 \mathrm{cc} / \mathrm{min}^{-}$ \\
\hline Temperature & Hyperthermia $\left(>38^{\circ} \mathrm{C}\right)$ & Normothermia to slight hyperthermia $\left(37-40^{\circ} \mathrm{C}\right)$ \\
\hline Limb environment during perfusion & Oxygenated, aerobic & Ischemic, anaerobic \\
\hline Ability to repeat & Difficult to repeat & Easily repeatable \\
\hline
\end{tabular}

\begin{tabular}{l} 
Table 2. Weiberdink grading system for measurement of melphalan-related toxic reactions. \\
\begin{tabular}{ll} 
Grade & Clinical signs and symptoms \\
\hline I & No reaction \\
\hline II & Slight erythema and/or edema \\
\hline III & \begin{tabular}{l} 
Considerable erythema and/or edema with some blistering; slightly disturbed motility permissible \\
\hline IV
\end{tabular} \\
\hline V & Rempartension epidermolysis and/or obvious damage to the deep tissues, causing definite functional disturbances; threatening or manifest \\
\hline
\end{tabular} \\
\hline
\end{tabular}

\section{Hyperthermic isolated limb perfusion}

Hyperthermic isolated limb perfusion (HILP) was initially described by Creech in 1959 and involves open dissection of the extremity inflow and outflow vessels and isolation using collateral vessel ligation. Large bore cannulas are placed under direct visualization and the limb is occluded by a pneumatic tourniquet above the level of cannula insertion [13]. Regional lymphadenectomy, if indicated, can be performed at the time of vascular dissection. The chemotherapy perfusate is heated, oxygenated and circulated at a high flow rate. The hyperthermic environment increases the cytotoxicity of melphalan, dosed at $10 \mathrm{mg} / \mathrm{l}$, with or without the addition of TNF- $\alpha$ or other experimental agents [10]. TNF- $\alpha$ is not available for use in the USA but is used widely in Europe, Australia and other countries.

The patient is systemically heparinized prior to cannula placement and inflow/outflow occlusion. Chemotherapy is administered with flow of 30-60 $\mathrm{ml} / 1 / \mathrm{min}$ for 45-90 min, while continuously monitoring temperature and venous pressures. Systemic leakage is measured using a precordial scintillation probe. After chemoperfusion, the limb is flushed with isotonic solution before releasing the tourniquet and removing access cannulas [13].

\section{Isolated limb infusion}

Isolated limb infusion (ILI) was initially described by Professor John Thompson in 1998 as a less invasive alternative to HILP. Vascular access is achieved percutaneously, bypass cannulas are smaller than in HILP, and an anaerobic, acidotic, normothermic environment is maintained [10]. Percutaneous catheters are placed above the most proximal disease but distal to planned tourniquet placement, and the patient is systemically heparinized. The infusion circuit includes a low flow roller pump or three-way stopcock with syringe (hand pump) and a heater. The extremities are also externally heated, routinely achieving $40^{\circ} \mathrm{C}$. The synergistic effect of hyperthermia, hypoxia and acidosis increases melphalan cytotoxicity 2.5-3.5-fold [10] Additionally, the low flow rate may provide more uniform drug distribution in target tissues. Drug doses are melphalan $7.5 \mathrm{mg} / \mathrm{l}$ for lower and $10 \mathrm{mg} / \mathrm{l}$ for upper extremity and actinomycin-D (Dactinomycin) at 75-100 mcg/l [14]. As in HILP, the limb is flushed with isotonic solution prior to tourniquet release.

\section{Peri-procedural complications \& adverse events}

Safety considerations with both HILP and ILI include complications of vascular access, limb toxicity and systemic chemotherapy delivery [15]. Vascular access problems can include bleeding, hematoma formation, pseudoaneurysm, thrombosis or embolization or vascular stenosis. Acute arterial thrombosis can occur in the immediate postoperative period, and necessitates return to the operating room for thrombectomy. Open groin access with HILP also entails risk of infection, seroma formation and lymphedema. Systemic toxicity should be rare with effective isolation of the extremity during either procedure. Bone marrow suppression can occur, but is especially rare with ILI.

Limb toxicities are graded using the Wieberdink extremity toxicity scale [12] (Table 2). Some limb erythema and edema are expected (categorized as grade 2 toxicity) and absence of these changes indicates underdosage of 


\begin{tabular}{|c|c|c|c|c|c|c|c|c|c|c|}
\hline Proc & Study setting & Study type & $\mathbf{N}$ & ORR (\%) & CR (\%) & Grade $\geq 3 \mathrm{AE}$ & PFS (mo) & OS (mo) & $\begin{array}{l}\text { 5-year surv } \\
(\%)\end{array}$ & Ref \\
\hline \multirow[t]{3}{*}{ HILP } & ACOSOG Z0020, USA, 1999-2004 & & & & & & & & & [18] \\
\hline & Melphalan & $\mathrm{RCT}$ & 58 & 64.0 & 25.0 & 3.0 & NR & NR & NR & \\
\hline & Melphalan/TNF- $\alpha$ & & 58 & 69.0 & 26.0 & 37.0 & & & & \\
\hline \multirow[t]{4}{*}{ HILP } & Europe, multi-center & & & & & & & & & [19] \\
\hline & Melphalan (historic control) & $\mathrm{RCT}$ & 103 & 78.0 & 52.0 & NR & NR & NR & NR & \\
\hline & Melphalan/TNF- $\alpha$ & & 32 & 91.0 & 69.0 & & 10.9 & 27.3 & & \\
\hline & Melphalan/TNF- $\alpha /$ IFN- $\gamma$ & & 32 & 100.0 & 78.0 & & 16.6 & 23.5 & & \\
\hline \multirow[t]{2}{*}{ HILP } & Germany, 1992-2003 & & & & & & & & & [20] \\
\hline & Melphalan/Dactinomycin & PC & 101 & 90.8 & 66.7 & NR & 21.0 & 42.0 & 38.0 & \\
\hline \multirow[t]{2}{*}{ HILP } & Netherlands, 1991-2003 & & & & & & & & & [21] \\
\hline & Melphalan/TNF- $\alpha$ & $\mathrm{RC}$ & 87 & 95.0 & 69.0 & 31.0 & NR & 25.0 & 32.0 & \\
\hline \multirow[t]{3}{*}{ HILP } & Netherlands, two centers & & & & & & & & & [22] \\
\hline & Melphalan & $\mathrm{RC}$ & 40 & 45.0 & 45.0 & 29.0 & 30.0 & 25.0 & 29.0 & \\
\hline & Melphalan/TNF- $\alpha$ & & 90 & 59.0 & 59.0 & 25.0 & 16.0 & & & \\
\hline ILI & $\begin{array}{l}\text { Australia, five institutions, } \\
\text { 1992-2008 }\end{array}$ & RC & 316 & 75.0 & 33.0 & 30.0 & NR & 44.0 & 46.0 & [16] \\
\hline ILI & $\begin{array}{l}\text { Moffitt Cancer Center, USA } \\
2007-2016\end{array}$ & PC & 148 & 59.0 & 25.7 & $11.9^{\dagger}$ & NR & 22.1 & NR & [23] \\
\hline ILI & Duke University, USA, 1995-2007 & PC & 61 & 44.0 & 30.0 & 18.0 & NR & NR & NR & [11] \\
\hline ILI & $\begin{array}{l}\text { Memorial Sloan Kettering, USA, } \\
\text { 1999-2011 }\end{array}$ & $\mathrm{PC} / \mathrm{RC}$ & 58 & 45.0 & 25.0 & NR & NR & 36.0 & 46.0 & {$[24,25]$} \\
\hline ILI & $\begin{array}{l}\text { International, nine institutions } \\
\text { 1992-2018 }\end{array}$ & $\mathrm{RC}$ & 687 & 64.1 & 28.9 & 27.9 & 10.1 & 38.2 & NR & [26] \\
\hline \multicolumn{11}{|c|}{$\begin{array}{l}\text { †Included patients with melanoma, squamous cell carcinoma, sarcoma and Merkel cell carcinoma. } \\
\text { AE: Adverse event; CR: Complete response; HILP: Hyperthermicisolated limb perfusion; ILI: Isolated limb infusion; mo: Month; NR: Not reported; ORR: Overall response rate; OS: Overall } \\
\text { survival; PC: Prospective cohort; PFS: Progression-free survival; Proc: Procedure; RC: Retrospective cohort; RCT: Randomized controlled trial; surv: Survival. }\end{array}$} \\
\hline
\end{tabular}

chemotherapy. The range of acceptable toxicity includes grades 1-3 reactions, while extensive epidermolysis, deep tissue damage, profound functional disturbances and compartment syndrome (grade 4) indicate an unacceptable level of toxicity. Compartment syndrome mandates return to the operating room to prevent limb loss. Grade 5 toxicity (may necessitate amputation) is a rare but devastating event which defeats the purpose of intra-arterial therapy for limb salvage [12].

Muscle ischemia can cause rhabdomyolysis, resulting in myoglobin-induced renal failure. CPK levels should be monitored post-procedure and are expected to peak 4 days post-procedure. In addition to ongoing observation and aggressive hydration, systemic steroids may be considered when CPK levels exceed $1000 \mu / 1$. Regional limb symptoms usually subside within $2-3$ weeks $[10,15]$.

Some patients are at higher risk for limb toxicity, including females and patients with larger limb volumes. Melphalan uptake is lower in fatty tissue, so patients with lower muscle to fat ratios can be inadvertently overdosed, resulting in increased limb toxicity [16]. Dose correction for ideal bodyweight decreases variability in mean drug concentration in perfused tissues and decreases regional limb toxicity without impacting response rates $[11,17]$.

\section{Outcomes of extremity intra-arterial therapies}

With unique technical expertise and equipment required to perform intra-arterial therapies, few centers routinely perform these procedures and have sufficient patient cohorts to publish their outcomes. Randomized controlled studies are scarce. Contemporary reports from these centers have established a fairly wide range of potential response rates but report uniformly low and predictable toxicities (Table 3).

\section{Efficacy of HILP}

Reported response rates for HILP vary widely. A systematic review included outcomes for over 2000 patients undergoing isolated limb perfusion for melanoma from 1990 to 2008 [27]. The majority (91\%) were observational studies, with only two randomized controlled trials identified. The collective median overall response rate (ORR) was $90 \%$, with $58 \%$ of patients having a complete response (CR). Responses were better with addition of TNF- $\alpha$ ( $69 \mathrm{vs} 47 \%$ ). Eighteen percent of patients experienced grade $\geq 3$ toxicity, including compartment syndrome in 25 $(2 \%)$ and toxicity-related amputation in $8(0.65 \%)$ [27]. 
The two available randomized controlled trials yielded lower overall and CR rates. One Netherlands-based study randomized 64 patients to HILP with melphalan plus TNF- $\alpha$ or melphalan, TNF- $\alpha$ and IFN- $\gamma$ [19]. Compared with a melphalan-only historic control, ORRs were 78, 91 and 100\% for melphalan, melphalan/TNF- $\alpha$, and melphalan/TNF- $\alpha / \mathrm{IFN}-\gamma$, respectively [19].

Response rates were lower from the US-based ACOSOG Z0020 randomized trial, which found no difference between melphalan alone (ORR: 64\%; CR: 25\%) and melphalan plus TNF- $\alpha$ (ORR: 69\%, CR: 26\%; p = 0.890) [18]. Toxicity was greater with the addition of TNF- $\alpha$, including two toxicity-related amputations among 68 patients [18].

\section{Efficacy of ILI}

A contemporary series including 316 procedures performed over a 15-year period at five Australian institutions demonstrated an ORR of 75\% [16]. Patients with CR had longer overall survival (OS) than those with PR (80 vs 36 months, HR: 2.56; 95\% CI: 1.67-3.09) [16]. In the USA, 148 ILI procedures for melanoma performed at Moffitt Cancer Center over a 10-year period demonstrated a slightly lower ORR of 59\% [23]. Again, responders had better outcomes, including longer in-field progression free survival (PFS) (14.1 vs 3.2 months, $\mathrm{p}<0.001)$, distant metastatic-free survival (not reached vs 25.8 months, $\mathrm{p}=0.006$ ) and OS (56 vs 26.7 months, $\mathrm{p}<0.001$ ). After ILI, 26\% of the population was resected to no evidence of disease [23].

A prospective series from Duke University included 61 consecutive ILI treatments performed from 1995 to 2007, demonstrating an ORR of 44\% with a longer median response duration of 24 months [11]. A smaller cohort from Memorial Sloan Kettering demonstrated a 52\% ORR among 31 patients with melanoma (26\% CR; $26 \%$ PR) [24]. Median response durations were 12 and 11 months after CR and PR. An updated cohort including 27 additional patients demonstrated a lower ORR of $45 \%$ [25]. The five-year survival for after CR was 91 versus $34 \%$ with PR, stable disease or progression [25].

In the largest report in the literature to date, an international, multi-institutional study recently examined the collective experience of first-time ILI for stage IIIB/C melanoma over a 27-year period. Among 687 cases, ORR was $64.1 \%$ and median OS was 38.2 months. Findings confirmed superior outcomes for responders compared with nonresponders, with longer in-field PFS (21.9 vs 3.0 months), distant PFS (53.6 vs 12.7 months) and OS (46.5 vs 24.4 months) [26].

\section{Comparison of outcomes for HILP versus ILI}

There have been no randomized comparisons of ILI and HILP, though efforts have been made to compare the procedures during different time periods within the same institution [11,28] and between institutions [29]. At Duke University, 59 HILPs performed from 1995 to 2003 were compared with 61 ILIs from 2003 to 2007. ORRs were better for HILP than ILI (ORR: 88 vs 44\%, p < 0.001; CR: 57 vs 30\%), but more patients experienced a grade $\geq 3$ toxicity (32 vs $18 \%, p=0.037$ ) including nine fasciotomies for suspected compartment syndrome and one amputation after HILP group versus none after ILI [11]. Updated results through 2010 including 72 HILPs and 144 ILIs demonstrated similar ORRs (81 vs 43\%; CR: 55 vs 30\%) but no difference in OS (32 vs 33 months, $\mathrm{p}=0.647)$ [28]. Grade $\geq 3$ toxicity was reported in $27 \%$ after HILP and $22 \%$ after ILI, including two post HILP amputations. There were more wound infections (13 vs $0 \%)$ and venous thromboembolic events (11 vs 4\%) with HILP [28].

A comparison of 94 ILIs performed at Moffitt Cancer Center (USA) and 109 HILPs at Sahlgrenska University Hospital (Sweden) from 2007 to 2015 also found higher ORR for HILP than ILI (80 vs 53\%) but similar OS (40 vs 46 months) [29]. The incremental improvement in OS in this more recent cohort might be attributable to more effective systemic therapies [29].

After intra-arterial therapy, approximately $20-50 \%$ of patients recur locoregionally [21,30,31]. Repeat HILPs have produced response rates of $72-96 \%(62-76 \%$ CR; $10-20 \%$ PR) with similar toxicity profiles to index procedures [30,32]. A benefit of ILI is that it can be repeated without the potential morbidity of re-operative open vessel cannulation. Repeat ILIs performed at a median of 11-14 months after the index procedure have response rates of $71-83 \%$ with fewer complete responders [31,33]. Some series report more grade $\geq 3$ toxicities after repeat ILI. In one study, $10.4 \%$ of patients experienced threatened or actual compartment syndrome (vs $2 \%$ with the initial ILI), but none required amputation [33]. A planned double ILI protocol (4 weeks after the initial infusion) did not improve ORR or response duration ( 88 vs $82 \%, 18$ vs 17 months), but toxicity was higher after second ILI (grade $\geq 3 ; 76$ vs $52 \%$ ) [31]. 
Table 4. Comparison of isolated hepatic perfusion and percutaneous hepatic perfusion.

\begin{tabular}{|c|c|c|}
\hline Technical aspect & Isolated hepatic perfusion & Percutaneous hepatic perfusion \\
\hline Technique & $\begin{array}{l}\text { Open, surgical vessel cannulation, IVC clamps } \\
\text { above/below liver }\end{array}$ & $\begin{array}{l}\text { Minimally invasive, percutaneous vessel cannulation, } \\
\text { fenestrated catheter in IVC with double balloons } \\
\text { above/below liver }\end{array}$ \\
\hline Temperature & Hyperthermic & Normothermic to slightly hyperthermic \\
\hline Perfusate environment & Aerobic, oxygenated & Anaerobic, ischemic \\
\hline Perfusion duration & $60 \mathrm{~min}$ & $30 \mathrm{~min}$ \\
\hline Ability to repeat & More difficult & Less difficult \\
\hline
\end{tabular}

Choice of ILI versus HILP should consider the patient's overall treatment plans and potential need for repeat procedures for recurrent unresectable regional disease. Based on a series of 44 patients undergoing repeat ILI or HILP at three institutions, a practical algorithm proposed initial ILI in most cases because it is less complex and more replicable. Exceptions might include high volume disease, for which HILP could improve ORR. For repeat procedures, patients with prior HILP or ILI can undergo repeat ILI or HILP, although HILP after HILP is difficult to perform [34].

\section{Predictors of response to intra-arterial therapy}

Lower burden of disease, measured by number and size of lesions, is associated with a higher response rates to both ILI and HILP [25]. Low disease burden also portends more CRs, longer PFS (6.9 vs 3.8 months) [35,36], and longer OS after ILI [29]. Other tumor factors associated with response to intra-arterial therapy include lower stage and thinner Breslow depth of the primary tumor [16]. Patients with lower mean limb volumes appear to respond better to intra-arterial therapies [23]. Response rates appear to be similar for upper and lower extremity ILI, though toxicity may be higher for lower extremity procedures [37].

\section{Intra-arterial hepatic perfusion}

Two strategies exist for hepatic perfusion of cytotoxic chemotherapy, which are options for patients with metastatic melanoma limited to the liver (Table 4). Metastases should comprise less than $50 \%$ of the liver parenchyma to mitigate risk of post-perfusion hepatic failure. For both, melphalan is perfused using an extracorporeal circuit with the patient on veno-venous bypass.

Isolated hepatic perfusion (IHP) is an open surgical technique that involves mobilization of the liver, arterial infusion via a cannula in the hepatic artery, venous drainage via a cannula in the retrohepatic vena cava and clamping of the inferior vena cava (IVC) above and below the liver. The patient is placed on veno-venous bypass using cannulas in the saphenous, portal and axillary veins [38]. Like HILP, the perfusion circuit includes a roller pump, membrane oxygenator and heat exchanger which enables a high flow $(>400 \mathrm{ml} / \mathrm{min})$, hyperthermic, aerobic perfusion environment [38].

Percutaneous hepatic perfusion (PHP) is a minimally invasive alternative involving hepatic arterial access via a femoral artery, with embolization of aberrant, accessory and proximate nonhepatic arterial branches to mitigate systemic chemoperfusion. Hepatic venous isolation is accomplished using a double balloon catheter inserted through a femoral vein, with the cephalad balloon positioned at the atrio-caval junction and the caudal balloon in the infrahepatic IVC above the level of the renal veins. The patient is systemically heparinized prior to balloon inflation and an activated clotting time of $>400$ is maintained throughout the procedure. Fenestrations in the double balloon catheter provide hepatic venous outflow to the extracorporeal circuit, which comprises a centrifugal pump and two activated charcoal filters. A separate post-filter venous return cannula is placed in an internal jugular or subclavian vein [38]. Typically, the left and right lobes are independently perfused via advancement of the arterial catheter into either arterial branch. After a 30-min infusion, a 30-min washout is performed prior to re-establishing systemic flow to and from the liver. Due to the minimally invasive approach and limited peri-procedural morbidity, PHP can be repeated.

IHP is associated with response rates of $37.5-66 \%$, with CRs seen in $0-10 \%$ [39-42] (Table 5). In available series, mortality can be as high as $27 \%$, mostly from post-procedure hepatic failure and sequelae of major ab- 
Table 5. Outcomes isolated hepatic perfusion and percutaneous hepatic perfusion for uveal melanoma liver metastases.

\begin{tabular}{|c|c|c|c|c|c|c|c|c|c|c|}
\hline Proc type & Study setting & Study type & N & $\begin{array}{l}\text { Number } \\
\text { of proc }\end{array}$ & ORR (\%) & CR (\%) & $\begin{array}{l}\text { Death } \\
(\%)\end{array}$ & $\begin{array}{l}\text { HPFS } \\
\text { (mo) }\end{array}$ & OS (mo) & Ref. \\
\hline IHP & $\begin{array}{l}\text { National Cancer Institute, USA, 1994-1999 } \\
\text { Melphalan } \\
\text { Melphalan/TNF- } \alpha\end{array}$ & $\begin{array}{l}\mathrm{PC} \\
\mathrm{Ph} \mathrm{I} / / \mathrm{II}\end{array}$ & $\begin{array}{l}11 \\
11\end{array}$ & 1 & $\begin{array}{l}70.0 \\
54.5\end{array}$ & $\begin{array}{l}0.0 \\
18.0\end{array}$ & 4.5 & $\begin{array}{l}6.0 \\
14.0\end{array}$ & 11.0 & [40] \\
\hline IHP & National Cancer Institute, USA, 1997-2002 & $\begin{array}{l}\mathrm{PC} \\
\mathrm{Ph} \mathrm{I} / \mathrm{II}\end{array}$ & 29 & 1 & 62.0 & 10.0 & 0.0 & 8.0 & 12.1 & [39] \\
\hline IHP & $\begin{array}{l}\text { Sahlgrenska University Hospital, Sweden, } \\
\text { 1985-2007 }\end{array}$ & $\mathrm{RC} / \mathrm{PC}$ & $27^{\dagger}$ & 1 & 70.0 & 7.4 & 27.0 & NR & 7.5 & [42] \\
\hline IHP & Erasmus University, Netherlands, 2002-2006 & PC & 8 & 1 & 37.5 & 0.0 & 0.0 & 6.0 & 11.0 & [41] \\
\hline PHP & National Cancer Institute, USA, 2001-2004 & $\begin{array}{l}\mathrm{PC} \\
\mathrm{PhI}\end{array}$ & 10 & $2.6^{\ddagger}$ & 50.0 & 20.0 & 0.0 & NR & NR & [44] \\
\hline PHP & Moffitt Cancer Center, USA, 2008-2013 & RC & 5 & 3 & NR & NR & 0.0 & 7.6 & $12.6^{\S}$ & [45] \\
\hline PHP & $\begin{array}{l}\text { National Cancer Institute, USA, 2006-2009 } \\
\text { PHP } \\
\text { Best alternative care }\end{array}$ & $\begin{array}{l}\mathrm{RCT} \\
\mathrm{Ph} \text { III }\end{array}$ & $\begin{array}{l}44 \\
49\end{array}$ & $\begin{array}{l}3 \\
\mathrm{~N} / \mathrm{A}\end{array}$ & $\begin{array}{l}34.0 \\
2.0\end{array}$ & $\begin{array}{l}0.0 \\
\mathrm{~N} / \mathrm{A}\end{array}$ & 3.2 & $\begin{array}{l}7.0 \\
1.6\end{array}$ & $\begin{array}{l}10.6 \\
10.0 \mathbb{I}\end{array}$ & [46] \\
\hline PHP & $\begin{array}{l}\text { Moffitt Cancer Center, USA \& University of } \\
\text { Southhampton, UK, 2008-2016 }\end{array}$ & $\mathrm{RC}$ & 51 & 2 & 49.0 & 5.9 & 0.0 & 9.1 & 15.3 & [47] \\
\hline \multicolumn{11}{|c|}{$\begin{array}{l}\text { †Collective results for metastatic melanoma from ocular (20), cutaneous (5) and anal (2) primaries. } \\
\text { ¥Collective results for ten patients with ocular melanoma liver metastases and } 18 \text { with other primary liver metastases. } \\
\text { \$Collective results for ten patients with liver metastases of varying primaries-five with ocular melanoma, one with cutaneous/unknown primary melanoma and one with leiomyosarcoma. } \\
\mathbb{I}_{57 \%} \text { in best alternative care arm crossed over to PHP. } \\
\text { CR: Complete response; Death: Treatment-related mortality; HPFS: Hepatic progression-free survival; IHP: Isolated hepatic perfusion; mo: Month; N: Sample size; ORR: Overall response } \\
\text { rate; OS: Overall survival; PC: Prospective cohort; Ph: Phase; PHP: Percutaneous hepatic perfusion; Proc: Procedure; Proc type: Procedure type; RC: Retrospective cohort; RCT: Randomized } \\
\text { controlled trial./p> }\end{array}$} \\
\hline
\end{tabular}

dominal surgery [39-43]. Responses have fairly short duration, with median PFS of 8-9 months and OS of 11-12 months $[39,40]$.

An initial Phase I trial of PHP at the USA National Cancer Institute demonstrated a 50\% response rate in ten patients with ocular melanoma (CR: 20\%) [44] (Table 5). A separate series of five patients, each undergoing a median of 3 PHPs at Moffitt Cancer Center, demonstrated a 48.6\% median decrease in hepatic tumor volume [45]. A subsequent multicenter Phase III study compared PHP (up to 6 perfusions at 4- to 8-week intervals) to best alternative care in 93 patients with unresectable ocular or cutaneous melanoma liver metastases [46]. PHP improved overall response (34 vs 2\%) and median hepatic PFS (7 vs 1.6 months) [46]. In a subsequent two-institution series of 51 patients undergoing PHP, 49.0\% responded. An additional 33.3\% had stable disease for at least 3 months [47]. Median OS was 15.3 months, $37.5 \%$ experienced a grade $\geq 3$ adverse event, and there were no treatment-related deaths. A multi-center, single-arm, Phase III study is currently evaluating safety, efficacy and quality of life in 80 patients (NCT02678572).

There are limited data comparing PHP with other liver-directed therapies for ocular melanoma liver metastases. In a retrospective comparison with Yttrium-90 (Y90) and chemoembolization (CE), PHP demonstrated longer hepatic PFS and overall PFS than Y90 or CE. OS was also longer (PHP 608 days vs Y90 295 days and CE 265 days), but not statistically significant [9].

\section{Conclusion}

Intra-arterial therapies enable regional delivery of chemotherapy while minimizing systemic toxicity. They are effective tools for treating regionally metastatic, in-transit cutaneous melanoma and uveal melanoma metastatic to the liver. For both extremity-based and liver-based therapies, minimally invasive techniques produce comparable oncologic outcomes while minimizing morbidity; further, they can be repeated with greater ease.

\section{Future perspective}

Intra-arterial therapy is a valuable tool in the comprehensive management of patients with locoregionally advanced cutaneous melanoma and liver metastases from uveal melanoma. For uveal melanoma metastases, liver-directed therapies including hepatic perfusions are the most effective treatment option, surpassing available systemic treatments. Future work is needed to establish the role of hepatic perfusion alongside other liver-directed therapies including radioembolization and chemoembolization. 
For cutaneous melanoma, intra-arterial therapies produce significant and durable responses for a large proportion of patients. With the advent of multiple effective treatments for metastatic and locally unresectable cutaneous melanoma including immune therapy, BRAF/MEK pathway inhibition and intralesional therapy, there is a unique opportunity to refine the role of intra-arterial chemoperfusion in patients' comprehensive treatment plans. An improved understanding of which patients are likely to respond to intra-arterial therapies could be used to individualize treatment sequencing or potentially combine therapies. For example, an initial regional approach to regionally metastatic disease may be ideal for those patients who are most likely to respond, reserving systemic therapy for patients with distant progression.

For both cutaneous and ocular melanoma, treatment selection and sequencing should be determined in a multidisciplinary and patient-centric fashion, including medical and radiation oncologists, surgeons, interventional radiologists, perfusionists and patients. With appropriate selection and orchestration, intra-arterial therapy can be performed safely with excellent outcomes.

\section{Executive summary}

\section{Background}

- Intra-arterial perfusion-based therapies enable regional delivery of chemotherapeutic agents while minimizing systemic toxicity.

- Regionally metastatic, in transit, cutaneous melanoma is common (5-15\%) and can be highly morbid. Extremity-based intra-arterial therapies are an important treatment option for unresectable and symptomatic locoregional disease.

- Metastatic uveal melanoma is unique in that it typically solely or predominantly involves the liver, making it an opportune target for regional therapy.

- The aim of this review was to summarize the techniques and outcomes of intra-arterial therapies for regionally metastatic cutaneous and uveal melanoma.

Intra-arterial therapies for recurrent cutaneous melanoma of the extremity

- Hyperthermic isolated limb perfusion (HILP - open and complex) and isolated limb infusion (ILI - minimally invasive, easily repeatable) are two strategies used to treat regionally metastatic melanoma in transit disease, confined to a limb.

- In both techniques, the circulation of the involved extremity is isolated and a chemotherapeutic agent (typically melphalan) is infused intra-arterially using an extracorporeal pump.

- The most common adverse events after extremity-based intra-arterial therapy are limb toxicities, which are characterized using the Weiberdink toxicity scale.

- Response rates reported in the literature for extremity-based therapies (HILP and ILI) range from 44 to $100 \%$, with 25 to $78 \%$ achieving complete response.

- Patients who respond to extremity-based intra-arterial therapies have been demonstrated to benefit from improved progression-free and overall survival.

- Some patients with recurrent locoregional disease respond to repeat intra-arterial therapy, though rates of overall and complete response are slightly lower than with initial procedure.

Intra-arterial hepatic perfusion

- Intra-arterial hepatic perfusion is an effective treatment option for uveal melanoma liver metastases, and can be performed using open (isolated hepatic perfusion) and percutaneous (PHP) approaches.

- Isolated hepatic perfusion is an open surgical technique that carries increased morbidity and cannot be repeated.

- PHP is a minimally invasive technique using a double balloon fenestrated catheter to isolate hepatic venous flow that can be repeated.

- In both procedures, hepatic flow is isolated and melphalan is delivered to the liver via an extracorporeal pump with the patient on veno-venous bypass.

- Intra-arterial hepatic perfusion is appropriate for patients with a liver metastatic burden $<50 \%$ of total liver parenchyma, which minimizes risk of post-perfusion hepatic failure.

- Percutaneous hepatic perfusion has been shown to produce longer hepatic progression-free survival than best alternative care in previous Phase III clinical trials.

Financial \& competing interests disclosure

The senior author receives research funding from Novartis and serves on the Advisory Board and Speakers Board for Array Biopharma. The authors have no other relevant affiliations or financial involvement with any organization or entity with a financial interest in or financial conflict with the subject matter or materials discussed in the manuscript apart from those disclosed.

No writing assistance was utilized in the production of this manuscript. 
Open access

This work is licensed under the Attribution-NonCommercial-NoDerivatives 4.0 Unported License. To view a copy of this license, visit http://creativecommons.org/licenses/by-nc-nd/4.0/

\section{References}

Papers of special note have been highlighted as: $\bullet$ of interest; $\bullet \bullet$ of considerable interest

1. Read RL, Haydu L, Saw RP et al. In-transit melanoma metastases: incidence, prognosis, and the role of lymphadenectomy. Ann. Surg. Oncol. 22(2), 475-481 (2015).

2. Pawlik TM, Ross MI, Johnson MM et al. Predictors and natural history of in-transit melanoma after sentinel lymphadenectomy. Ann. Surg. Oncol. 12(8), 587-596 (2005).

3. Francken AB, Accortt NA, Shaw HM et al. Prognosis and determinants of outcome following locoregional or distant recurrence in patients with cutaneous melanoma. Ann. Surg. Oncol. 15(5), 1476-1484 (2008).

4. Cohen VM, Carter MJ, Kemeny A, Radatz M, Rennie IG. Metastasis-free survival following treatment for uveal melanoma with either stereotactic radiosurgery or enucleation. Acta. Ophthalmol. Scand. 81(4), 383-388 (2003).

5. Kujala E, Makitie T, Kivela T. Very long-term prognosis of patients with malignant uveal melanoma. Invest. Ophthalmol. Vis. Sci. 44(11), 4651-4659 (2003).

6. Gragoudas ES, Egan KM, Seddon JM et al. Survival of patients with metastases from uveal melanoma. Ophthalmology 98(3), 383-389; discussion 390 (1991).

7. Kath R, Hayungs J, Bornfeld N, Sauerwein W, Hoffken K, Seeber S. Prognosis and treatment of disseminated uveal melanoma. Cancer 72(7), 2219-2223 (1993).

8. Rajpal S, Moore R, Karakousis CP. Survival in metastatic ocular melanoma. Cancer 52(2), 334-336 (1983).

9. Abbott AM, Doepker MP, Kim Y et al. Hepatic progression-free and overall survival after regional therapy to the liver for metastatic melanoma. Am. J. Clin. Oncol. 41(8), 747-753 (2018).

10. Thompson JF, Kam PC, Waugh RC, Harman CR. Isolated limb infusion with cytotoxic agents: a simple alternative to isolated limb perfusion. Semin. Surg. Oncol. 14(3), 238-247 (1998).

\section{-• Landmark article describing the technique andinitial results of isolated limb infusion}

11. Beasley GM, Petersen RP, Yoo J et al. Isolated limb infusion for in-transit malignant melanoma of the extremity: a well-tolerated but less effective alternative to hyperthermic isolated limb perfusion. Ann. Surg. Oncol. 15(8), 2195-2205 (2008).

12. Wieberdink J, Benckhuysen C, Braat RP, Van Slooten EA, Olthuis GA. Dosimetry in isolation perfusion of the limbs by assessment of perfused tissue volume and grading of toxic tissue reactions. Eur. J. Cancer. Clin. Oncol. 18(10), 905-910 (1982).

- Of interest

13. Creech O, Jr., Krementz ET, Ryan RF, Winblad JN. Chemotherapy of cancer: regional perfusion utilizing an extracorporeal circuit. Ann. Surg. 148(4), 616-632 (1958).

- Of interest

14. Beasley GM, Caudle A, Petersen RP et al. A multi-institutional experience of isolated limb infusion: defining response and toxicity in the US. J. Am. Coll. Surg. 208(5), 706-715; discussion 715-707 (2009).

15. Moller MG, Lewis JM, Dessureault S, Zager JS. Toxicities associated with hyperthermic isolated limb perfusion and isolated limb infusion in the treatment of melanoma and sarcoma. Int. J. Hyperthermia 24(3), 275-289 (2008).

16. Kroon HM, Coventry BJ, Giles MH et al. Australian multicenter study of isolated limb infusion for melanoma. Ann. Surg. Oncol. 23(4), 1096-1103 (2016).

17. Santillan AA, Delman KA, Beasley GM et al. Predictive factors of regional toxicity and serum creatine phosphokinase levels after isolated limb infusion for melanoma: a multi-institutional analysis. Ann. Surg. Oncol. 16(9), 2570-2578 (2009).

18. Cornett WR, Mccall LM, Petersen RP et al. Randomized multicenter trial of hyperthermic isolated limb perfusion with melphalan alone compared with melphalan plus tumor necrosis factor: American College of Surgeons Oncology Group Trial Z0020. J. Clin. Oncol. 24(25), 4196-4201 (2006).

19. Lienard D, Eggermont AM, Koops HS et al. Isolated limb perfusion with tumour necrosis factor-alpha and melphalan with or without interferon-gamma for the treatment of in-transit melanoma metastases: a multicentre randomized Phase II study. Melanoma Res. 9(5), 491-502 (1999).

20. Knorr C, Meyer T, Janssen T, Goehl J, Hohenberger W. Hyperthermic isolated limb perfusion (HILP) in malignant melanoma. Experience with 101 patients. Eur. J. Surg. Oncol. 32(2), 224-227 (2006).

21. Grunhagen DJ, Brunstein F, Graveland WJ, Van Geel AN, De Wilt JH, Eggermont AM. One hundred consecutive isolated limb perfusions with TNF- $\alpha$ and melphalan in melanoma patients with multiple in-transit metastases. Ann. Surg. 240(6), 939-947; discussion 947-938 (2004). 
22. Noorda EM, Vrouenraets BC, Nieweg OE, Van Geel BN, Eggermont AM, Kroon BB. Isolated limb perfusion for unresectable melanoma of the extremities. Arch. Surg. 139(11), 1237-1242 (2004).

23. O'donoghue C, Perez MC, Mullinax JE et al. Isolated limb infusion: a single-center experience with over 200 infusions. Ann. Surg. Oncol. 24(13), 3842-3849 (2017).

24. Brady MS, Brown K, Patel A, Fisher C, Marx W. Isolated limb infusion with melphalan and dactinomycin for regional melanoma and soft-tissue sarcoma of the extremity: final report of a Phase II clinical trial. Melanoma Res. 19(2), 106-111 (2009).

25. Steinman J, Ariyan C, Rafferty B, Brady MS. Factors associated with response, survival, and limb salvage in patients undergoing isolated limb infusion. J. Surg. Oncol. 109(5), 405-409 (2014).

26. Miura Jt KH, Beasley Gm et al. Long-term oncologic outcomes following isolated limb infusion for loco-regionally metastatic melanoma: an international multicenter analysis. Reg. Cancer Ther.(2019) (Epub ahead of print).

-. This is another landmark article where multiple centers across the globe combined to show with nearly 700 patients their isolated limb infusion results. We have showed this technique can result in long-term durable complete responses that positively affects the overall survival for this population With metastatic melanoma in and in transit fashion confined to the limb.

27. Moreno-Ramirez D, De La Cruz-Merino L, Ferrandiz L, Villegas-Portero R, Nieto-Garcia A. Isolated limb perfusion for malignant melanoma: systematic review on effectiveness and safety. Oncologist 15(4), 416-427 (2010).

28. Raymond AK, Beasley GM, Broadwater G et al. Current trends in regional therapy for melanoma: lessons learned from 225 regional chemotherapy treatments between 1995 and 2010 at a single institution. J. Am. Coll. Surg. 213(2), 306-316 (2011).

29. Dossett LA, Ben-Shabat I, Olofsson Bagge R, Zager JS. Clinical response and regional toxicity following isolated limb infusion compared with isolated limb perfusion for in-transit melanoma. Ann. Surg. Oncol. 23(7), 2330-2335 (2016).

30. Grunhagen DJ, Van Etten B, Brunstein F et al. Efficacy of repeat isolated limb perfusions with tumor necrosis factor alpha and melphalan for multiple in-transit metastases in patients with prior isolated limb perfusion failure. Ann. Surg. Oncol. 12(8), 609-615 (2005).

31. Lindner P, Thompson JF, De Wilt JH, Colman M, Kam PC. Double isolated limb infusion with cytotoxic agents for recurrent and metastatic limb melanoma. Eur. J. Surg. Oncol. 30(4), 433-439 (2004).

32. Noorda EM, Vrouenraets BC, Nieweg OE, Van Geel AN, Eggermont AM, Kroon BB. Repeat isolated limb perfusion with TNFalpha and melphalan for recurrent limb melanoma after failure of previous perfusion. Eur. J. Surg. Oncol. 32(3), 318-324 (2006).

33. Kroon HM, Lin DY, Kam PC, Thompson JF. Efficacy of repeat isolated limb infusion with melphalan and actinomycin D for recurrent melanoma. Cancer 115(9), 1932-1940 (2009).

34. Chai CY, Deneve JL, Beasley GM et al. A multi-institutional experience of repeat regional chemotherapy for recurrent melanoma of extremities. Ann. Surg. Oncol. 19(5), 1637-1643 (2012).

\section{- Of interest}

35. Muilenburg DJ, Beasley GM, Thompson ZJ, Lee JH, Tyler DS, Zager JS. Burden of disease predicts response to isolated limb infusion with melphalan and actinomycin D in melanoma. Ann. Surg. Oncol. 22(2), 482-488 (2015).

36. Alexander HR Jr, Fraker DL, Bartlett DL et al. Analysis of factors influencing outcome in patients with in-transit malignant melanoma undergoing isolated limb perfusion using modern treatment parameters. J. Clin. Oncol. 28(1), 114-118 (2010).

37. Beasley GM, Sharma K, Wong J et al. A multi-institution experience comparing the clinical and physiologic differences between upper extremity and lower extremity melphalan-based isolated limb infusion. Cancer 118(24), 6136-6143 (2012).

38. Alexander HR Jr, Butler CC. Development of isolated hepatic perfusion via the operative and percutaneous techniques for patients with isolated and unresectable liver metastases. Cancer J. 16(2), 132-141 (2010).

\section{$\bullet \quad$ Of considerable interest}

39. Alexander HR Jr, Libutti SK, Pingpank JF et al. Hyperthermic isolated hepatic perfusion using melphalan for patients with ocular melanoma metastatic to liver. Clin. Cancer Res. 9(17), 6343-6349 (2003).

40. Alexander HR, Libutti SK, Bartlett DL, Puhlmann M, Fraker DL, Bachenheimer LC. A Phase I-II study of isolated hepatic perfusion using melphalan with or without tumor necrosis factor for patients with ocular melanoma metastatic to liver. Clin. Cancer Res. 6(8), 3062-3070 (2000).

41. Van Etten B, De Wilt JH, Brunstein F, Eggermont AM, Verhoef C. Isolated hypoxic hepatic perfusion with melphalan in patients with irresectable ocular melanoma metastases. Eur. J. Surg. Oncol. 35(5), 539-545 (2009).

42. Rizell M, Mattson J, Cahlin C, Hafstrom L, Lindner P, Olausson M. Isolated hepatic perfusion for liver metastases of malignant melanoma. Melanoma Res. 18(2), 120-126 (2008).

43. Deneve JL, Choi J, Gonzalez RJ et al. Chemosaturation with percutaneous hepatic perfusion for unresectable isolated hepatic metastases from sarcoma. Cardiovasc. Intervent. Radiol. 35(6), 1480-1487 (2012).

44. Pingpank JF, Libutti SK, Chang R et al. Phase I study of hepatic arterial melphalan infusion and hepatic venous hemofiltration using percutaneously placed catheters in patients with unresectable hepatic malignancies. J. Clin. Oncol. 23(15), 3465-3474 (2005).

45. Forster MR, Rashid OM, Perez MC, Choi J, Chaudhry T, Zager JS. Chemosaturation with percutaneous hepatic perfusion for unresectable metastatic melanoma or sarcoma to the liver: a single institution experience. J. Surg. Oncol. 109(5), 434-439 (2014). 
46. Hughes MS, Zager J, Faries M et al. Results of a randomized controlled multicenter Phase III trial of percutaneous hepatic perfusion compared with best available care for patients with melanoma liver metastases. Ann. Surg. Oncol. 23(4), 1309-1319 (2016).

-. Phase 3 clinical trial results showing apositive clinical trial where percutaneous hepatic perfusion significantly outperformed best alternative care for patients with ocular or cutaneous metastatic melanoma isolated to deliver in terms of progression free survival. Patients on the percutaneous hepatic perfusion arm had a five times greater hepatic progression free survival and a significantly better overall progression free survival then best alternative care

47. Karydis I, Gangi A, Wheater MJ et al. Percutaneous hepatic perfusion with melphalan in uveal melanoma: a safe and effective treatment modality in an orphan disease. J. Surg. Oncol. 117(6), 1170-1178 (2018). 